\title{
Evaluation of unmanned aerial vehicle shape, flight path and camera type for waterfowl surveys: disturbance effects and species recognition
}

John F McEvoy, Graham P Hall, Paul G McDonald

The use of unmanned aerial vehicles (UAVs) for ecological research has grown rapidly in recent years, but few studies have assessed the disturbance impacts of these tools on focal subjects, particularly when observing easily disturbed species such as waterfowl. In this study, we assessed the level of disturbance that a range of UAV shapes and sizes had on free-living waterfowl, as well as the capability of airborne digital imaging systems to provide adequate resolution for unambiguous species identification of these taxa. We found little or no obvious disturbance effects on wild, mixed-species flocks of waterfowl when UAVs were flown at least $60 \mathrm{~m}$ above the water level (fixed wing models) or $40 \mathrm{~m}$ above individuals (multirotor models). Disturbance in the form of swimming away from the UAV through to leaving the water surface and flying away from the UAV was visible at lower altitudes and when fixed-wing UAVs either approached subjects directly or rapidly changed altitude and/or direction near animals. Using tangential approach flight paths that did not cause disturbance, commercially available onboard optical equipment was able to capture images of sufficient quality to identify waterfowl and even much smaller taxa such as swallows. Our results show that with proper planning of take-off and landing sites, flight paths and careful UAV model selection, UAVs can provide an excellent tool for accurately surveying wild waterfowl populations and provide archival data with fewer logistical issues than traditional methods such as manned aerial surveys. 


\section{Evaluation of unmanned aerial vehicle shape, flight path and camera type for waterfowl surveys: disturbance effects and species recognition}

John F. McEvoy ${ }^{1 *}$, Graham P. Hall ${ }^{1}$, Paul G. McDonald ${ }^{1}$

\section{Author Details:}

${ }^{1}$ Centre for Behavioural and Physiological Ecology, Zoology, University of New England, Armidale, NSW, Australia, 2351

${ }^{*}$ Corresponding author:

John F. McEvoy

Email: johnfmcevoy@gmail.com 
1 Abstract

2 The use of unmanned aerial vehicles (UAVs) for ecological research has grown rapidly in recent

3 years, but few studies have assessed the disturbance impacts of these tools on focal subjects,

4 particularly when observing easily disturbed species such as waterfowl. In this study, we

5 assessed the level of disturbance that a range of UAV shapes and sizes had on free-living, non-

6 breeding waterfowl surveyed in two sites in eastern Australia between March and May 2015, as

7 well as the capability of airborne digital imaging systems to provide adequate resolution for

8 unambiguous species identification of these taxa. We found little or no obvious disturbance

9 effects on wild, mixed-species flocks of waterfowl when UAVs were flown at least 60m above

10 the water level (fixed wing models) or 40m above individuals (multirotor models). Disturbance in

11 the form of swimming away from the UAV through to leaving the water surface and flying away

12 from the UAV was visible at lower altitudes and when fixed-wing UAVs either approached

13 subjects directly or rapidly changed altitude and/or direction near animals. Using tangential

14 approach flight paths that did not cause disturbance, commercially available onboard optical

15 equipment was able to capture images of sufficient quality to identify waterfowl and even much

16 smaller taxa such as swallows. Our results show that with proper planning of take-off and landing

17 sites, flight paths and careful UAV model selection, UAVs can provide an excellent tool for

18 accurately surveying wild waterfowl populations and provide archival data with fewer logistical

19 issues than traditional methods such as manned aerial surveys. 
Introduction

21 Aerially sourced data is critical to the understanding and census of many ecological systems, such

22 as the use of remotely sensed satellite imagery to investigate the impacts of climate change or the

23 movement ecology of nomadic species (Bartlam-Brooks et al. 2013; Blanco et al. 2008; Felix N

24 2000; Mueller et al. 2011; Roshier \& Rumbachs 2004) or estimating population sizes using aerial

25 photography (Bako et al. 2014; Trathan 2004). Research targeting waterfowl populations is no

26 exception. In this field, conservation and management policies concerning agricultural mitigation

27 interventions or harvest seasons are heavily reliant upon accurate population counts that are

28 typically taken from manned aerial surveys, particularly in countries such as Australia where

29 water bodies are often ephemeral and widely dispersed (Kingsford et al. 2011; USFWS 2009). To

30 date, most waterfowl surveys of large water bodies are undertaken using fixed wing aircraft

31 carrying trained observers (Kingsford 1999; Petrie et al. 2002). The reliability of results from

32 aerial surveys can depend on the experience and training of observers, variation in detectability of

33 different species, and the disturbance caused by flying an aircraft over a wetland at low altitude

34 and high speed (Caughley 1974; Fleming \& Tracey 2008). While there are many advantages to

35 the use of satellite imagery, ground images can often be obscured by cloud or have poor

36 coverage, and be difficult to access for researchers in some countries. Satellite imagery is often

37 sufficient for larger taxa, such as several mammal species on the African savannah (Yang et al.

38 2014) but is considered unsuitable for smaller taxa such as waterfowl (Conant et al. 2007).

39 In recent years rapid advances in the quality, availability and range of sensors in commercial

40 unmanned aerial vehicles (UAVs) have lead to their widespread use in the fields of ecology and

41 conservation (Anderson \& Gaston 2013; Chabot \& Bird 2015; Goebel et al. 2015; Jones et al.

42 2006). UAVs can provide a cheaper, safer and less labour intensive approach compared to

43 traditional aerial surveys and while a single survey flight may cover less ground than a standard 
44 aerial survey they can be used to target specific areas of interest with greater precision and with

45 lower workplace safety risks to employees than travel in manned aircraft entails. Applications

46 include biodiversity assessments (Getzin et al. 2012), counting of colonial species (Grenzdoerffer

47 2013; Ratcliffe et al. 2015; Sarda-Palomera et al. 2012), observations of target species for 48 conservation management (Brooke et al. 2015; Ditmer et al. 2015; Hodgson et al. 2013; Koh \&

49 Wich 2012; Vermeulen et al. 2013)and fine scale sensing of habitat composition (Chabot et al.

50 2014) and environmental variables in inaccessible terrain (Berni et al. 2009). With the increase in

51 the deployment of UAVs, particularly in the study of vulnerable or sensitive species, there is a

52 need to balance the potential disturbance to the animals present with the benefits gained from

53 close observation. The application of UAVs for wildlife surveys is a rapidly advancing field and

54 in 2015 alone there have been several studies that have attempted to quantify the response of

55 animals in wild situations to the presence of an overhead UAV (Chabot et al. 2015; Ditmer et al.

56 2015; Goebel et al. 2015; Pomeroy et al. 2015; Vas et al. 2015). In the studies published to date

57 that have examined this question, researchers have often relied on a single type of UAV (typically

58 a small multirotor model) without comparing potential disturbance effects of the different fixed

59 wing and multi-rotor UAVs that are commercially available. Given the different acoustic profiles,

60 flight patterns and shape of available platforms, it would be unwise to extrapolate a focal species'

61 response or tolerance between different models of UAVs, such as multirotor versus fixed wing

62 configurations, as animals may react very differently to each type.

63 A further advantage of UAVs that is seldom raised is that the aerial photography based approach

64 provides a bank of images from which individual species can be independently counted, verified

65 and archived for future analysis or audit. This creates a transparent census technique that

66 increases the usability and cost effectiveness of information gathered if images are made

67 available to other researchers. While aerial photography taken from both manned aircraft and 
68 UAVs has proven effective for monitoring large terrestrial mammals (Terletzky \& Ramsey 2014;

69 Vermeulen et al. 2013), identifying much smaller and often more mobile avian taxa to species has

70 thus far proved more challenging. This is particularly true for the identification of waterfowl, due

71 to the relative small size of these birds, their camouflaged plumage and similarity in shape and

72 colouration across species (particularly for females and males in eclipse plumage). The

73 acquisition of the high quality images needed to overcome this challenge has been limited by the

74 resolution and portability of available digital cameras that can be carried by commercially 75 available UAVs.

76 Recent technological advances appear to have overcome these issues, so the present study had

77 two central aims: 1) To assess disturbance effects on waterfowl from various UAV models that

78 may render a survey invalid, and 2) to assess whether an airborne digital imaging system could

79 provide adequate resolution for unambiguous identification of small bodied waterfowl.

\section{Materials and Methods}

81 This work was carried out under scientific permits from the New South Wales Office of

82 Environment and Heritage (licence no.: SL101457) and was approved by the University of New

83 England Animal Ethics Committee (authority no. : AEC14-104).

\section{Study Sites}

85 Field tests of disturbance from UAVs were undertaken at two locations in New South Wales,

86 Australia between March and May 2015 with both sites visited on a total of 6 separate occasions.

87 Little Llangothlin Lagoon (Fig 1) is a permanent natural wetland in the north east of the state (S-

$8830.086277^{\circ}, \mathrm{E} 151.783650^{\circ}$ ); it is a protected Ramsar wetland that provides an important refuge

89 for numerous waterfowl species during drought. The lagoon is $1 \mathrm{~km}^{2}$ in area, with approximately

90 half of the water surface covered with vegetation. The surrounds are characterised by a narrow

91 band of eucalypt dominated open woodland and agricultural pasture (Fig 1). Whilst the bird 
92 community composition did fluctuate between visits, the same species were observed at each

93 survey and included all typical waterfowl for the region. Total bird numbers regularly exceeded

942000 individuals, with a minimum of 1000 ducks seen at each visit. The most common waterfowl

95 observed included Eurasian coot (Fulica atra), Pacific black duck (Anas superciliosa), grey teal

96 (Anas gracilis), hardhead (Aythya australis), Australasian shoveler (Anas rhynchotis), pink-eared

97 duck (Malacorhynchus membranaceus), musk duck (Biziura lobata), blue billed duck (Oxyura

98 australis) and black swan (Cygnus atratus). For a complete species list for each site see

99 supplementary material. While birds were present in every area of the lake, distribution of taxa

100 was not uniform; for example dabbling duck species (Anas sp.) were more common near the

101 shore with diving birds and swans preferring open water.

102 The second site was at the town of Lake Cargelligo in the south east of New South Wales (S-

$10333.313264^{\circ}, \mathrm{E} 146.382210^{\circ}$; Fig 2). This water body is a $24 \mathrm{~km}^{2}$ lake that is managed by local

104 authorities to maintain consistent water levels year round. The main lake supports populations of

105 Australian pelican (Pelecanus conspicillatus) and Australian darter (Anhinga novaehollandiae)

106 but the majority of waterfowl in the region congregate at the adjacent sewage works (Fig 2).

107 Sewage ponds are rich in nutrients and protected from disturbance and often form a focal point

108 for waterfowl in many areas of Australia (Hamilton \& Taylor 2004; McEvoy et al. 2015; Murray

109 et al. 2012). The sewage works $\left(0.2 \mathrm{~km}^{2}\right)$ consists of constructed ponds of varying turbidity,

110 separated by gravel embankments that provided areas for roosting of waterfowl, surrounded by a

111 dense border of Typha spp. rushes. Bird numbers at the sewage works remained stable at

112 approximately 40 individuals at each visit, including grey teal, pink-eared duck, Pacific black

113 duck, hardhead and black swan. During the day the majority of waterfowl were found basking on

114 embankments between ponds rather than on the water surface, providing a contrast to the Little

115 Llangothlin Lagoon site. Both study sites were regularly visited by a range of avian predators 
116 including white-bellied sea-eagle (Haliaeetus leucogaster), marsh harrier (Circus approximans)

117 and whistling kite (Haliastur sphenurus), all of which prey on small bodied waterfowl (Baker-

118 Gabb 1984; Marchant \& Higgins 1990). None of the species at either site were observed to be

119 breeding.

\section{UAV Models and Flights}

121 In total 5 different UAV models of different shapes and sizes were tested in this study to

122 determine if the shape of the model used would elicit different responses from birds (Table 1).

123 These models included fixed wing UAVs with different wing profiles (e.g.: delta wing, glider

124 type) and multirotor UAVs from the small, widely used DJI Phantom quadcopter to the larger

125 more powerful Kraken-130 multirotor UAV (Fig 3). Each UAV had a unique take- off and

126 landing system, with fixed wing systems requiring a larger clear area for both take-off and

127 landing, launching systems such as bungee cords or rails along with landing airbags, parachutes

128 or nets. The multirotor models could take-off and land vertically from almost any location. Flight

129 time and flight speed also varied between UAV models. Flight time for the fixed wing models

130 was between 60-90 minutes per flight, whereas flight time for multirotor models was often $<20$

131 minutes per flight. Fixed wing UAVs moved at a speed of approximately $40 \mathrm{~km} / \mathrm{hr}$ while

132 multirotor UAVs moved at approximately $5 \mathrm{~km} / \mathrm{hr}$.

133 At Little Llangothlin Lagoon UAVs were launched from two sites; one within 10m of the shore

134 and another $500 \mathrm{~m}$ from the shore, with the latter behind a small rise and thus out of sight of birds

135 on the lagoon. UAVs were launched either directly towards flocks of birds on the lagoon, or

136 approached the lagoon at a tangential angle (Fig 1). Flights were undertaken at a maximum

137 altitude of $120 \mathrm{~m}$ and a minimum of $40 \mathrm{~m}$ above the lagoon. During flights, each UAV was

138 programmed to fly across the lagoon in a linear north-south direction at a given altitude, before

139 changing in altitude by $10 \mathrm{~m}$ over land approximately $50 \mathrm{~m}$ from the lagoon edge and returning on 
140 the opposite north-south route for the next pass (Fig 1). Altitudes were tested in ascending and

141 descending order to determine if the birds responded differently to the UAV initially entering the

142 area at lower or higher altitudes. Each UAV undertook two test flights for each combination of

143 approach angle and take off conditions.

144 At Lake Cargelligo UAVs were launched from a clear site 300m from the edge of the water out of 145 sight of the birds. Flights were all launched away from the birds due to prevailing wind 146 conditions and flight paths were flown parallel to the embankments where most birds were found.

147 As at Little Llangothlin Lagoon, each UAV carried out a range of passes at ascending and 148 descending altitudes between $120 \mathrm{~m}$ and 40m. Each UAV undertook two test flights for each 149 combination of approach angle and take off conditions. The Phantom multirotor UAV showed 150 poor results, with birds swimming away from the UAV such that they were not captured on 151 images taken vertically below the unit (Table 2). Further, this unit's battery life saw it incapable 152 of carrying out a full survey of the lake, and as such it was not used in further flights. Due to time 153 constraints, technical problems with the UAV operators' equipment and poor weather conditions, 154 some UAVs were not used at both sites (Table 4). The Kraken and Phantom multirotor UAVs 155 were tested at Lake Cargelligo, while the Avian-P and Topodrone-100 were tested at Little 156 Llangothlin Lagoon. The Skylark UAV was tested at both locations. The total numbers of birds at

157 Lake Cargelligo was smaller (as the water body was not as large) but the same species were 158 recorded and the UAV was tested over a wild, mixed flock of birds.

159 At both sites, disturbance of the birds was monitored during the same flights used to capture 160 digital imagery by two observers at vantage points that covered the entire water body using 161 binoculars, telescopes and video cameras to observe and record any responses to the UAVs or to 162 natural predators in the area. Disturbance was categorised into three categories: "NR" was used if 163 birds showed no discernible response to the UAV, "V" was used if birds ceased foraging, either 
164 orientating or looking towards the UAV or, in some cases, slowly swimming away from the

165 stimulus, or "F" if birds took flight in response to the approaching UAV. No differences in

166 disturbance measures were observed according to whether the UAV was descending or ascending

167 at each pass; hence for simplicity presented results combine both vectors (Table 2).

\section{Digital Imaging}

169 Four types of digital camera were mounted to the various UAV models to assess their capability

170 to capture high quality images of waterfowl against natural backgrounds (Table 3). In all cases

171 the camera was mounted in a gimbal (a pivoted support frame) to allow the camera to remain 172 stable regardless of any turbulence during flight. The physical limitations of each UAV, such as

173 the power to lift camera payloads and attachments, determined the size and shape of camera that

174 could be fitted. Images were digitally recorded to on-board memory cards and downloaded to a 175 laptop in the field upon completion of the flight for preliminary assessment. Adjustments to 176 optimise images via camera setting changes were then made if necessary for subsequent flights.

177 Images from each flight were examined independently by the three authors (all experienced in 178 waterfowl identification) to determine the species present in each image. If there was not 179 unanimous agreement between the three authors as to the species shown in a given image, it was 180 considered to be unusable.

\section{Results}

182 Disturbance

183 Across both study sites and all UAV models, the level of disturbance caused was generally

184 minimal (Table 2). The most extreme category of a flight response by focal waterfowl away from 185 the UAVs was rarely observed, but was typically encountered when the UAV was launched 186 directly at a flock of birds at a low altitude during take-off (10-15m). During the course of the 187 study resident raptors were observed to fly across both study sites, actively hunting at similar 
188 altitudes to those flown by the UAVs. These raptors elicited immediate flight responses from the

189 flocks of waterfowl present, with most birds on the lake taking flight as the raptors flew

190 overhead. The flight response to the UAVs, when it did occur, included birds flying away from

191 shore at low altitude for short periods to settle on open water. In contrast, the response to the

192 arrival of a raptor was far more marked, with large flocks of birds taking flight and flying for

193 longer periods high above the water before resettling.

194 The shape and wing profile of each UAV model appeared to influence the response of waterfowl.

195 The UAV with a delta-wing design (Topodrone-100) caused the greatest level of disturbance and

196 flee behaviour (Table 2 and 4), particularly when it directly approached birds during take-off or in

197 a direct, rather than tangential path $(\leq 80 \mathrm{~m}$ altitude) or made a banking manoeuvre while changing

198 altitude (dropping from $70 \mathrm{~m}$ to $60 \mathrm{~m}$, for example). These flight periods resemble those of a

199 swooping raptor that is banking to swoop upon prey, and the design of the UAV to human eyes

200 was very similar in dihedral and shape to that of the larger raptors hunting waterfowl (Fig 3F).

201 Disturbance from multi-rotor UAVs was more subtle; the DJI Phantom multirotor, when flown at

$20215 \mathrm{~m}$ altitude, resulted in birds swimming away from the UAV when approached. Birds remained

203 vigilant and continuously swam ahead of the field of view of the on-board video camera without

204 taking flight. The larger 8-rotor system (Kraken-130) caused little disturbance at any altitude. The

205 only recorded response occurred at $40 \mathrm{~m}$ altitude where roosting birds could be seen to tilt their

206 heads to look up at the UAV, but no further response was noted and birds continued roosting or

207 preening activities (see Pacific black duck in Fig 4).

208 Digital Imaging

209 Of the four different camera systems that were trialled only two configurations provided adequate

210 results. The Phase 1 medium format camera equipped with an 80mm lens and 50 megapixel

211 sensor produced images of high resolution (Fig 4 , ground cover $=5.5 \mathrm{~mm} / \mathrm{pixel}$ at $60 \mathrm{~m}$ altitude) 
212 that allowed for the unambiguous identification of very similar species of ducks, as well as

213 smaller non-target species including passerines. The Sony A7-R camera with a 36 megapixel

214 sensor and 50-70mm lens provided images of comparable resolution to the Phase 1 with a slight

215 but noticeable reduction in resolution (Fig 5, ground cover $=7.2 \mathrm{~mm} /$ pixel at $50 \mathrm{~m}$ altitude). The

216 other camera systems suffered from either a lack of resolution (e.g. the Sony RX-1, ground cover

$217=25 \mathrm{~mm} /$ pixel at $60 \mathrm{~m}$ altitude) and/or technical issues such as motion blur or focusing problems

218 due to software errors or changing light conditions. Unexpected rainfall within a single flight

219 provided images where identification to species level was not possible. For example, the

220 "mvBlueCOUGAR-X" camera could not be programmed to adjust settings 'on the fly' meaning

221 that once programmed prior to takeoff, the camera could not adjust for any change in conditions.

222 This was impractical, as changes in light were frequent when a cloud passed in front of the sun,

223 or glare from the water surface reached the lens. As a result, this camera provided very poor

224 quality images that were not suitable for species identification. 
225 Discussion

226 Many studies have quantified anthropogenic disturbance to wild birds from stimuli such as

227 pedestrians and vehicles (McLeod et al. 2013; Moller et al. 2014). With the increasing popularity 228 of UAVs for ecological research in the past year, there has been a sharp increase in papers 229 assessing the potential for disturbance of wild animals by UAVs (Ditmer et al. 2015; Dulava et al. 230 2015; Pomeroy et al. 2015; Vas et al. 2015; Weissensteiner et al. 2015). Waterfowl are known to

231 be sensitive to disturbance, with relatively high values of flight initiation distance (FID) 232 compared to other species (Bregnballe et al. 2009; Korschgen \& Dahlgren 1992; Madsen 1995; 233 Weston et al. 2012). Few studies have assessed the disturbance effects of UAVs on waterfowl in 234 wild or natural settings. Studies such as Chabot and Bird (2012) and Vas et al (2015) used off235 the-shelf UAVs to approach flocks of Canada Geese (Branta canadensis) and Snow Geese (Chen 236 caerulescens) (Chabot \& Bird 2012) semi-wild mallard (Anas platyrhynchos) (Vas et al. 2015), 237 with minimal disturbance recorded. In another recent study by Drever et al (2015) using a single 238 rotor UAV flying at $>60 \mathrm{~m}$ altitude, disturbance also appeared to be minimal. With the rapid 239 increase in the application of UAVs for ecological research, it important to gain a broader 240 understanding of their disturbance impacts on different species in wild situations. Our study

241 builds on these results and is the first to directly compare the disturbance effects across two 242 different sized water bodies from a range of medium sized UAVs used to carry camera equipment 243 ranging from widely available off the shelf cameras to high-end medium format commercial 244 cameras. The UAVs tested in this study cover a range of body shapes and wing profiles that may 245 be deployed for ecological fieldwork. We tested these UAVs in a natural setting with large mixed

246 flocks of different species of water birds, and we observed that multirotor UAVs had minimal 247 disturbance effects. However, fixed-wing UAVs performed better in collecting aerial photography 248 and were more practical to deploy for larger scale surveys, as long as they were flown in a 249 manner that minimised the potential for disturbance. 
250 On repeated flights at varying altitude with different UAV models our results show that if flown

251 with care and attention to potential sources of disturbance, UAVs can prove an effective solution

252 for aerial surveys of waterfowl populations (Table 2). Our findings demonstrate that if take-off

253 and landing occur out of sight of the target species and the UAV has reached its survey altitude

254 before crossing into view of the birds, disturbance was minimal, and much quieter than manned

255 fixed-wing aircraft (Fleming \& Tracey 2008). Mixed-species flocks of wild birds were observed

256 to take flight in response to a UAV that was launched from the take-off site toward the flock at

257 low altitude $(<40 \mathrm{~m})$. Birds were observed to tolerate a UAV descending from $120 \mathrm{~m}$ to $40 \mathrm{~m}$

258 altitude, but only if any banking manoeuvres while turning and descending did not occur directly

259 above the flock (Table 4). 
260 It has long been thought that birds, and waterfowl in particular, react differently to silhouettes of

261 predators (e.g. raptors) and non-predators (e.g. geese) flying above them. Early studies

262 (Tinbergen 1939) found that naïve birds reacted differently to 'hawk' and 'goose' silhouettes but

263 these findings were later re-assessed (Schleidt et al. 2011) and found to be a reaction to novel

264 shapes that disappeared with experience. The outline of the 4 and 8 rotor multirotor UAVs used

265 in this study represented novel shapes that did not resemble any identifiable bird group to our

266 eyes, and these UAVs caused no flight response in waterfowl, with only a mild swimming

267 response at very low altitudes $(15 \mathrm{~m})$. Two of the fixed wing UAVs used in this study, in

268 particular the "Avian-P" model (Fig 3 A), presented an outline that closely resembled that of a

269 non-predatory swan to human observers experienced in waterfowl identification. These 'glider-

270 type' UAVs caused no disturbance to large flocks of waterfowl when flown overhead at a steady

271 altitude, including flights at the lower limit of the UAV (60m above water level). The delta-wing

272 type UAV (Fig 3C) presented an outline resembling raptors that regularly hunt waterfowl at the

273 study sites, particularly when banking and changing altitude where it caused birds to fly away

274 from the shore toward open water, a typical response to a swooping raptor for these species (pers.

275 obs.). This study afforded us the opportunity to observe responses to actual avian predators as

276 well, including white-bellied sea eagles (Fig 3 F) that have a very similar wingspan and wing

277 shape to the UAVs used. Even though some UAVs had a passing resemblance in silhouette to

278 predators, the arrival of an actual predator resulted in a mass take-off of the mixed flock of birds

279 that was more marked than UAV-evoked responses. Our findings suggest that even though UAVs

280 represent novel objects in the air above them wild birds do not react to them as strongly as they

281 do to typical aerial predators.

282 Legislation governing the use of UAVs in public areas has lagged behind their increasing

283 popularity, although some positive changes in regulations have taken place recently (Allan et al. 
284 2015). While small 'off the shelf' UAVs with limited range and payload capacity are appropriate

285 for many ecological applications, such as checking the status of nests in hard to reach places

286 (Junda et al. 2015; Potapov et al. 2013; Weissensteiner et al. 2015), larger scale projects require a

287 more specialised and correspondingly larger UAV to carry appropriate equipment and achieve

288 viable flight times (Chabot et al. 2014). For most researchers this will mean collaborating with a

289 commercial UAV company in order to ensure the technical expertise needed to pilot more

290 complex systems and all relevant aviation permits are in place. While there has been rapid growth

291 in the commercial UAV industry we found that many of the UAV companies are, at least in south-

292 eastern Australia, focused on industrial applications such as mining or civil engineering projects

293 that have vastly different technical requirements to most ecological fieldwork. As a consequence,

294 one of the initial barriers to effectively carrying out aerial surveys of this kind was in

295 communicating effectively with commercial UAV operators the different requirements of

296 working with mobile taxa as opposed to collecting imagery of static geographical features. Future

297 researchers should bear this in mind, and have detailed conversations with companies concerning

298 disturbance, approach angles, take-off and landing sites to avoid costly delays and inaccurate data

299 collection.

300 High resolution digital images allowing the easy identification of waterfowl species were

301 produced by both the Phase-1 camera (Fig 4) and the Sony A7-R (Fig 5) in our trials. Although

302 the images produced by the Phase-1 were of a noticeably higher resolution, the much greater cost

303 (approximately AU\$40,000) and size may prove prohibitive for many researchers. Large

304 multirotor UAVs are capable of carrying heavy payloads and can take-off and land vertically in

305 almost any terrain without causing disturbance to waterfowl, however their current short battery

306 life seriously limits their feasibility for surveys of large areas, including even moderately sized

307 water bodies. Single rotor UAVs capable of vertical take-off and landing have been deployed 
308 with flight times close to 30 minutes and faster air speeds than many multirotor systems (Drever

309 et al. 2015) but these UAVs are not as widely available to researchers. Despite this, the low

310 disturbance effects of these UAV designs mean that researchers should consider their use if the

311 current constraints of these models are not too restrictive and a suitable flight time/camera

312 payload can be used.

313 One of the biggest advantages of using UAVs to collect high quality digital images is that it

314 allows researchers to archive the results of each survey for future reference, re-assessment,

315 validation, or meta-analysis. While automated systems for counting birds from aerial photographs

316 have been in use for some time (Bajzak \& Piatt 1990), they are generally limited to counting

317 individuals of a single species or colonial birds showing strong contrast with their visual

318 background (Abd-Elrahman et al. 2005; Descamps et al. 2011; Groom et al. 2011; Rodgers et al.

319 2005; Trathan 2004). The task of automatically identifying species of similar size, shape, and

320 colouration from large mixed flocks remains a serious challenge to overcome. Developing

321 versatile algorithms to identify and count a variety of waterfowl species in different habitat

322 settings will be a key area of future research in this field.

323 When attempting to accurately identify waterfowl to species using UAV photography there are

324 many trade-offs that must be considered. Ideally, using a very high resolution camera such as the

325 Phase 1 medium format camera (50 megapixels) allows the UAV to fly at higher altitudes

326 covering a large area footprint $(40 \mathrm{~m} \times 30 \mathrm{~m}$ at $60 \mathrm{~m}$ altitude) with a medium focal length lens

$327(80 \mathrm{~mm})$ and still gather images of suitable quality (Figure 4). Due to constraints of budget or the

328 maximum payload of the available UAVs, it may not be possible to fly with a large high

329 resolution camera such as the Phase 1 camera used in this study. Problems with lower resolution

330 could be overcome by flying the UAV lower or by using longer lenses, but this needs to be

331 balanced against potential disturbance as well as a reduction in the overall footprint covered by 
332 each image. We also observed an increased potential for image blurring when using longer lenses

333 at lower altitudes. We used the Sony A7-R camera (36 megapixels) with a 70mm lens at 50m

334 altitude and captured images that allowed for easy identification of waterfowl to species (Figure

335 5) with a slight reduction in the area footprint of each image $(30 \mathrm{~m} \times 20 \mathrm{~m})$. Further trade-offs

336 occur with the choice of UAV when considering the ability of the UAV to survey a large water

337 body in a short period of time, the ability to carry the necessary camera equipment and whether

338 the shape, wing profile or flight behaviour of the UAV are likely to disturb the target animals.

339 Based on our findings, the best results for successfully surveying a medium sized $\left(>1 \mathrm{~km}^{2}\right)$

340 wetland and easily identifying waterfowl would come from a combination of a digital camera

341 with a minimum 36 megapixel full frame sensor combined with a fixed wing UAV with long

342 straight wings to cover large wetlands in a single survey. That is not to say that other

343 combinations of UAVs and cameras are unsuitable, but that this combination appears to offer the

344 longest flying time combined with high quality imagery suitable for species identification at an

345 approximate resolution of $7.2 \mathrm{~mm}$ per pixel that was required to achieve our desired accuracy in

346 identification. Prior to deployment, careful consideration should be given to all of the trade-offs

347 mentioned above before embarking on a waterfowl survey using UAVs, as different conditions or

348 availability of hardware may necessitate a slightly different approach. Where possible, the take-

349 off and landing sites should be carefully selected to remain out of sight of the target birds and

350 flight paths should be programmed to approach tangentially to the main flock of birds. Where

351 possible, any turning manoeuvres or sharp drops in altitude should be performed away from the

352 shore with the UAV flying at a fixed altitude across the study area to minimise any potential for

353 disturbance.

\section{Acknowledgements}


355 UAV surveys were carried out with the assistance of a number of commercial companies: UAV

356 Geomatics Australia, Airsight Australia, Flight Data Systems, and UAViation Australia. We are

357 indebted to the National Parks and Wildlife Service, NSW and Lachlan Shire Council for their

358 assistance with accessing study sites. We are grateful to a number of people for their assistance

359 with field work: Koen Dijkstra, Milla Mihailova, Ahmad Barati, Louise Streeting, Sigrid

360 Mackenzie and Alice Bauer.

\section{References}

362 Abd-Elrahman A, Pearlstine L, and Percival F. 2005. Development of pattern recognition algorithm for automatic bird detection from unmanned aerial vehicle imagery. Surveying and Land Information Science 65:37.

Allan BM, Ierodiaconou D, Nimmo DG, Herbert M, and Ritchie EG. 2015. Free as a drone: ecologists can add UAVs to their toolbox. Frontiers in Ecology and the Environment 13:354-355. 10.1890/15.wb.015

Anderson K, and Gaston KJ. 2013. Lightweight unmanned aerial vehicles will revolutionize spatial ecology. Frontiers in Ecology and the Environment 11:138-146. 10.1890/120150

Bajzak D, and Piatt JF. 1990. Computer-aided procedure for counting waterfowl on aerial photographs. Wildlife Society Bulletin:125-129.

Baker-Gabb D. 1984. The feeding ecology and behaviour of seven species of raptor overwintering in coastal Victoria. Wildlife Research 11:517-532.

Bako G, Tolnai M, and Takacs A. 2014. Introduction and Testing of a Monitoring and ColonyMapping Method for Waterbird Populations That Uses High-Speed and Ultra-Detailed Aerial Remote Sensing. Sensors 14:12828-12846. 10.3390/s140712828

Bartlam-Brooks HLA, Beck PSA, Bohrer G, and Harris S. 2013. In search of greener pastures: using satellite images to predict the effects of environmental change on zebra migration. Journal of Geophysical Research: Biogeosciences:n/a-n/a. 10.1002/jgrg.20096

Berni JAJ, Zarco-Tejada PJ, Suarez L, and Fereres E. 2009. Thermal and Narrowband Multispectral Remote Sensing for Vegetation Monitoring From an Unmanned Aerial Vehicle. Ieee Transactions on Geoscience and Remote Sensing 47:722-738. 10.1109/tgrs.2008.2010457

Blanco PD, Rostagno CsM, del Valle HcF, Beeskow AM, and Wiegand T. 2008. Grazing Impacts in Vegetated Dune Fields: Predictions From Spatial Pattern Analysis. Rangeland Ecology \& Management 61:194-203. doi:10.2111/06-063.1

Bregnballe T, Speich C, Horsten A, and Fox AD. 2009. An experimental study of numerical and behavioural responses of spring staging dabbling ducks to human pedestrian disturbance. Wildfowl:131-142.

Brooke S, Graham D, Jacobs T, Littnan C, Manuel M, and O'Conner R. 2015. Testing marine conservation applications of unmanned aerial systems (UAS) in a remote marine protected area. Journal of Unmanned Vehicle Systems 3:237-251. 10.1139/juvs-2015-0011

Caughley G. 1974. Bias in aerial survey. The Journal of Wildlife Management:921-933. 
394

395

396

397

398

399

400

401

402

403

404

405

406

407

408

409

410

411

412

413

414

415

416

417

418

419

420

421

422

423

424

425

426

427

428

429

430

431

432

433

434

435

436

437

438

439

440

441

442
Chabot D, and Bird DM. 2012. Evaluation of an off-the-shelf Unmanned Aircraft System for Surveying Flocks of Geese. Waterbirds 35:170-174. 10.1675/063.035.0119

Chabot D, and Bird DM. 2015. Wildlife research and management methods in the 21st century: Where do unmanned aircraft fit in? Journal of Unmanned Vehicle Systems 3:137-155. 10.1139/juvs-2015-0021

Chabot D, Carignan V, and Bird DM. 2014. Measuring Habitat Quality for Least Bitterns in a Created Wetland with Use of a Small Unmanned Aircraft. Wetlands 34:527-533. 10.1007/s13157-014-0518-1

Chabot D, Craik SR, and Bird DM. 2015. Population Census of a Large Common Tern Colony with a Small Unmanned Aircraft. Plos One 10:e122588.

Conant B, Groves DJ, and Moser TJ. 2007. Distribution and abundance of wildlife from fixedwing aircraft surveys in Nunavut, Canada, June 2006. US Fish and Wildlife Service.

Descamps S, Béchet A, Descombes X, Arnaud A, and Zerubia J. 2011. An automatic counter for aerial images of aggregations of large birds. Bird Study 58:302-308.

Ditmer MA, Vincent JB, Werden LK, Tanner JC, Laske TG, Iaizzo PA, Garshelis DL, and Fieberg JR. 2015. Bears Show a Physiological but Limited Behavioral Response to Unmanned Aerial Vehicles. Current Biology 25:2278-2283. 10.1016/j.cub.2015.07.024

Drever MC, Chabot D, O'Hara PD, Thomas JD, Breault A, and Millikin RL. 2015. Evaluation of an unmanned rotorcraft to monitor wintering waterbirds and coastal habitats in British Columbia, Canada. Journal of Unmanned Vehicle Systems 3:256-267. 10.1139/juvs-20150019

Dulava S, Bean WT, and Richmond OMW. 2015. Applications of Unmanned Aircraft Systems (UAS) for Waterbird Surveys. Environmental Practice 17:201-210. $10.1017 / \mathrm{s} 1466046615000186$

Felix N K. 2000. Satellite-Observed Sensitivity of World Land Ecosystems to El Niño/La Niña. Remote Sensing of Environment 74:445-462.

Fleming PJS, and Tracey JP. 2008. Some human, aircraft and animal factors affecting aerial surveys: how to enumerate animals from the air. Wildlife Research 35:258-267. 10.1071/wr07081

Getzin S, Wiegand K, and Schoning I. 2012. Assessing biodiversity in forests using very highresolution images and unmanned aerial vehicles. Methods in Ecology and Evolution 3:397-404. 10.1111/j.2041-210X.2011.00158.x

Goebel ME, Perryman WL, Hinke JT, Krause DJ, Hann NA, Gardner S, and LeRoi DJ. 2015. A small unmanned aerial system for estimating abundance and size of Antarctic predators. Polar Biology:1-12.

Grenzdoerffer GJ. 2013. UAS-based automatic bird count of a common gull colony. In: Grenzdorffer G, and Bill R, eds. Uav-G2013, 169-174.

Groom G, Krag Petersen I, Anderson MD, and Fox AD. 2011. Using object-based analysis of image data to count birds: mapping of Lesser Flamingos at Kamfers Dam, Northern Cape, South Africa. International journal of remote sensing 32:4611-4639.

Hamilton AJ, and Taylor IR. 2004. Distribution of foraging waterbirds throughout Lake Borrie ponds at the Western Treatment Plant, Victoria (Australia). Victorian Naturalist 122:6878.

Hodgson A, Kelly N, and Peel D. 2013. Unmanned Aerial Vehicles (UAVs) for Surveying Marine Fauna: A Dugong Case Study. Plos One 8. e79556

10.1371/journal.pone.0079556

Jones GP, Pearlstine LG, and Percival HF. 2006. An assessment of small unmanned aerial vehicles for wildlife research. Wildlife Society Bulletin 34:750-758. 10.2193/00917648(2006)34[750:aaosua]2.0.co;2 
443

444

445

446

447

448

449

450

451

452

453

454

455

456

457

458

459

460

461

462

463

464

465

466

467

468

469

470

471

472

473

474

475

476

477

478

479

480

481

482

483

484

485

486

487

488

489

490

491
Junda J, Greene E, and Bird DM. 2015. Proper flight technique for using a small rotary-winged drone aircraft to safely, quickly, and accurately survey raptor nests. Journal of Unmanned Vehicle Systems 3:222-236. 10.1139/juvs-2015-0003

Kingsford RT. 1999. Aerial survey of waterbirds on wetlands as a measure of river and floodplain health. Freshwater Biology 41:425-438. 10.1046/j.1365-2427.1999.00440.x

Kingsford RT, Porter JL, and Halse SA. 2011. National Waterbird Asssessment. Waterlines Report. Canberra: National Water Commission.

Koh LP, and Wich SA. 2012. Dawn of drone ecology: low-cost autonomous aerial vehicles for conservation. Tropical Conservation Science 5:121-132.

Korschgen CE, and Dahlgren RB. 1992. Human disturbances of waterfowl: causes, effects, and management. Waterfowl Management Handbook. p 1-9.

Madsen J. 1995. Impacts of disturbance on migratory waterfowl. Ibis 137:S67-S74.

Marchant S, and Higgins PJ. 1990. Handbook of Australian, New Zealand, and Antarctic Birds. Vol. 2. Oxford: Oxford University Press.

McEvoy J, Roshier D, Ribot R, and Bennett A. 2015. Proximate cues to phases of movement in a highly dispersive waterfowl, Anas superciliosa. Movement Ecology 3:21.

McLeod EM, Guay P-J, Taysom AJ, Robinson RW, and Weston MA. 2013. Buses, Cars, Bicycles and Walkers: The Influence of the Type of Human Transport on the Flight Responses of Waterbirds. Plos One 8:e82008.

Moller AP, Samia DSM, Weston MA, Guay PJ, and Blumstein DT. 2014. American Exceptionalism: Population Trends and Flight Initiation Distances in Birds from Three Continents. Plos One 9. e107883

10.1371/journal.pone.0107883

Mueller T, Olson KA, Dressler G, Leimgruber P, Fuller TK, Nicolson C, Novaro AJ, Bolgeri MJ, Wattles D, DeStefano S, Calabrese JM, and Fagan WF. 2011. How landscape dynamics link individual- to population-level movement patterns: a multispecies comparison of ungulate relocation data. Global Ecology and Biogeography:no-no. 10.1111/j.14668238.2010.00638.x

Murray CG, Loyn RH, Kasel S, Hepworth G, Stamation K, and Hamilton AJ. 2012. What can a database compiled over 22 years tell us about the use of different types of wetlands by waterfowl in south-eastern Australian summers? Emu 112:209-217.

Petrie SA, Shannon SB, and Wilcox KL. 2002. Population Trends and Habitat Use of Tundra Swans Staging at Long Point, Lake Erie. Waterbirds: The International Journal of Waterbird Biology 25:143-149.

Pomeroy P, O'Connor L, and Davies P. 2015. Assessing use of and reaction to unmanned aerial systems in gray and harbor seals during breeding and molt in the UK. Journal of Unmanned Vehicle Systems 3:102-113. 10.1139/juvs-2015-0013

Potapov E, Utekhina I, McGrady M, and Rimlinger D. 2013. Usage of UAV for Surveying Steller's Sea Eagle Nests. Raptors Conservation.

Ratcliffe N, Guihen D, Robst J, Crofts S, Stanworth A, and Enderlein P. 2015. A protocol for the aerial survey of penguin colonies using UAVs. Journal of Unmanned Vehicle Systems 3:95-101. 10.1139/juvs-2015-0006

Rodgers JA, Kubilis PS, and Nesbitt SA. 2005. Accuracy of Aerial Surveys of Waterbird Colonies. Waterbirds 28:230-237. 10.1675/1524-4695(2005)028[0230:aoasow]2.0.co;2

Roshier DA, and Rumbachs RM. 2004. Broad-scale mapping of temporary wetlands in arid Australia. Journal of Arid Environments 56:249-263.

Sarda-Palomera F, Bota G, Vinolo C, Pallares O, Sazatornil V, Brotons L, Gomariz S, and Sarda F. 2012. Fine-scale bird monitoring from light unmanned aircraft systems. Ibis 154:177183. 10.1111/j.1474-919X.2011.01177.x 
492 Schleidt W, Shalter MD, and Moura-Neto H. 2011. The hawk/goose story: the classical

493

494

495

496

497

498

499

500

501

502

503

504

505

506

507

508

509

510

511

512

513

514

515

516 ethological experiments of Lorenz and Tinbergen, revisited. Journal of Comparative Psychology 125:121.

Terletzky P, and Ramsey RD. 2014. A Semi-Automated Single Day Image Differencing Technique to Identify Animals in Aerial Imagery. Plos One 9:e85239.

Tinbergen N. 1939. Why do birds behave the way they do? Bird Lore 41:23-30.

Trathan PN. 2004. Image analysis of color aerial photography to estimate penguin population size. Wildlife Society Bulletin 32:332-343. 10.2193/00917648(2004)32[332:iaocap]2.0.co;2

USFWS. 2009. Waterfowl Population Status, 2009. In: U.S. Fish and Wildlife Service DoMBM, editor.

Vas E, Lescroel A, Duriez O, Boguszewski G, and Gremillet D. 2015. Approaching birds with drones: first experiments and ethical guidelines. Biology Letters 11. 20140754

10.1098/rsbl.2014.0754

Vermeulen C, Lejeune P, Lisein J, Sawadogo P, and Bouché P. 2013. Unmanned Aerial Survey of Elephants. Plos One 8:e54700.

Weissensteiner MH, Poelstra JW, and Wolf JBW. 2015. Low-budget ready-to-fly unmanned aerial vehicles: an effective tool for evaluating the nesting status of canopy-breeding bird species. Journal of Avian Biology 46:425-430. 10.1111/jav.00619

Weston MA, McLeod EM, Blumstein DT, and Guay PJ. 2012. A review of flight-initiation distances and their application to managing disturbance to Australian birds. Emu 112:269286. 10.1071/mu12026

Yang Z, Wang TJ, Skidmore AK, de Leeuw J, Said MY, and Freer J. 2014. Spotting East African Mammals in Open Savannah from Space. Plos One 9. e115989

10.1371/journal.pone.0115989 
517 Figure Legends

518 Fig 1. Little Llangothlin Lagoon, NSW, Australia. Approximately $50 \%$ of the surface is

519 vegetated and large numbers of birds (>1000) were distributed across the lagoon. A) Yellow

520 circles represent take-off sites. White arrows represent approach angles for different flights. B)

521 One example of a flight path across the lake. Take-off site was away from the edge of the lake

522 and the target altitude was reached before crossing over water. As far as possible any banking or

523 changes in altitude were carried out away from the water. Map data: Google, DigitalGlobe

524 Fig 2. Lake Cargelligo, NSW, Australia. The main lake is approximately $24 \mathrm{~km}^{2}$ and is

525 managed to maintain water levels. The majority of waterfowl in the area congregate on the local

526 sewage works (inset) where all UAV trials were carried out. A) Yellow circle represents take-off

527 site. White arrows represent approach angles for different flights. B) One example of a flight path

528 across the sewage works. Take-off site was away from the edge of the water and the target

529 altitude was reached before crossing over water. As far as possible any banking or changes in

530 altitude were carried out away from the water. Map data: Google, DigitalGlobe

531 Fig 3. Examples of UAV models with different wing profiles. A) Avian-P fixed wing UAV, B)

532 Skylark II fixed wing UAV, C) Topodrone-100 fixed wing UAV, resembles bird of prey, D)

533 Kraken-130 multirotor type UAV, E) Phantom multirotor type UAV, F) White-bellied sea eagle, a 534 common avian predator active at each study site.

535 Fig 4. Examples of images taken using the Phase-1 medium format digital camera. Species

536 that are similar in size and shape can be clearly differentiated in photos taken from 60m above the

537 flock with an $80 \mathrm{~mm}$ lens. Smaller birds such as swallows and black winged stilts can also be

538 easily identified. In the bottom right panel a Pacific black duck can be seen tilting its head to look 
539 directly up at the camera. This image was captured with an ISO $=400$, shutter speed $=1 / 800$ s and

$540 \mathrm{f}$-stop= 11 The area footprint of this image is $40 \mathrm{~m} \times 30 \mathrm{~m}$ with ground coverage of $5.5 \mathrm{~mm} / \mathrm{pixel}$.

541 Fig 5. Examples of images taken using the Sony A7-R digital camera. Species that are similar

542 in size and shape can be clearly differentiated in photos taken from 50m above the flock with a

$54370 \mathrm{~mm}$ lens. Smaller birds such as swallows and black winged stilts can also be easily identified.

544 The area footprint of this image is $30 \mathrm{~m} \times 20 \mathrm{~m}$ with ground coverage of $7.2 \mathrm{~mm} / \mathrm{pixel}$. This image

545 was captured with an ISO $=200$, shutter speed $=1 / 640$ s and f-stop $=6.3$ 


\section{Table 1 (on next page)}

UAV models used for test flights and their associated characteristics 
1 Table 1. UAV models used for test flights and their associated characteristics.

\begin{tabular}{|c|c|c|c|c|c|c|}
\hline UAV & Body Shape & $\begin{array}{c}\text { Mass } \\
(\mathrm{kg})\end{array}$ & Take-off & $\begin{array}{l}\text { Wingspan/D } \\
\text { iameter (m) }\end{array}$ & $\begin{array}{c}\text { Max Flight } \\
\text { Speed } \\
(\mathrm{km} / \mathrm{hr})\end{array}$ & $\begin{array}{c}\text { Battery Life } \\
\text { (min) }\end{array}$ \\
\hline $\begin{array}{l}\text { UAVER } \\
\text { Avian-P }\end{array}$ & & 4.7 & $\begin{array}{c}\text { Launch } \\
\text { Rack + } \\
\text { Bungee } \\
\text { Cord }\end{array}$ & 1.6 & 63 & $60-90$ \\
\hline Skylark II & & 4 & $\begin{array}{c}\text { Hand + } \\
\text { Bungee } \\
\text { Cord }\end{array}$ & 3 & 40 & $60-90$ \\
\hline $\begin{array}{c}\text { Drone } \\
\text { Metrex } \\
\text { Topodrone- } \\
100\end{array}$ & & 4.5 & $\begin{array}{c}\text { Launch Rail } \\
+ \text { Bungee } \\
\text { Cord }\end{array}$ & 2 & 80 & 60 \\
\hline DJI & & 1.2 & Vertical & 0.4 & 10 & 15 \\
\hline $\begin{array}{c}\text { FoxTech } \\
\text { Kraken-130 }\end{array}$ & & 6 & Vertical & 1.8 & 10 & 15 \\
\hline
\end{tabular}

2 


\section{Table 2 (on next page)}

Response of mixed flocks of waterfowl to UAVs of different shapes flying overhead at various altitudes

For fixed wing UAVs the lower altitudes $(15 \mathrm{~m})$ represent take-off where the UAV was launched directly towards the birds before gaining height. NR (green squares) $=$ No discernible response, $\mathrm{V}$ (yellow squares $)=$ Vigilance response detected, $\mathrm{F}($ red squares $)=$ Flight response. Cells are marked "N/A" where a given UAV did not fly over birds at that altitude. 
1 Table 2. Response of mixed flocks of waterfowl to UAVs of different shapes flying overhead

2 at various altitudes. For fixed wing UAVs the lower altitudes $(15 \mathrm{~m})$ represent take-off where

3 the UAV was launched directly towards the birds before gaining height. NR (green squares) =

4 No discernible response, $\mathrm{V}$ (yellow squares) = Vigilance response detected, $\mathrm{F}$ (red squares) =

5 Flight response. Cells are marked "N/A" where a given UAV did not fly over birds at that

6 altitude.

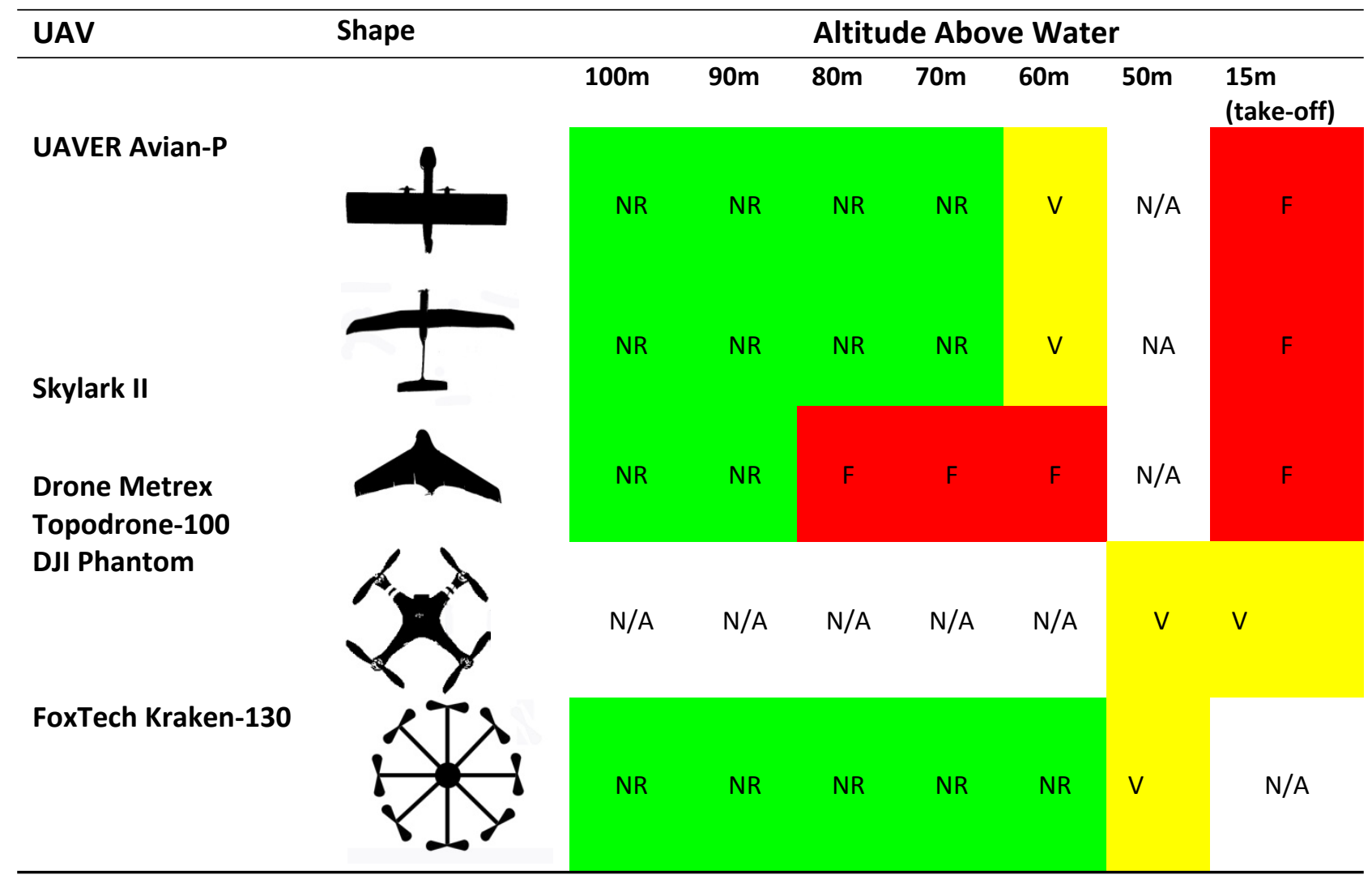

7 
Table 3 (on next page)

Specifications of camera models used in test flights 
1 Table 3. Specifications of camera models used in test flights

\begin{tabular}{|c|c|c|c|c|}
\hline Camera & UAV & Focal Length & $\begin{array}{c}\text { Resolution } \\
\text { (megapixel) }\end{array}$ & Sensor \\
\hline Sony RX-1 & $\begin{array}{c}\text { UAVER } \\
\text { Avian-P } \\
\text { \& Drone } \\
\text { Metrex } \\
\text { Topodrone- } \\
100 \text { - Fixed } \\
\text { Wing }\end{array}$ & $35 \mathrm{~mm}$ & 24.3 & Full Frame CMOS \\
\hline $\begin{array}{l}\text { mvBlueCOUGAR- } \\
x\end{array}$ & $\begin{array}{l}\text { Skylark II - } \\
\text { Fixed Wing }\end{array}$ & $100 \mathrm{~mm}$ & 10.1 & Full Frame CCD \\
\hline Sony A7-R & $\begin{array}{c}\text { FoxTech } \\
\text { Kraken-130 - } \\
\text { Multirotor }\end{array}$ & $35-70 \mathrm{~mm}$ & 36.4 & Full Frame CMOS \\
\hline Phase 1 & $\begin{array}{c}\text { FoxTech } \\
\text { Kraken-130 - } \\
\text { Multirotor }\end{array}$ & $80 \mathrm{~mm}$ & 50 & Medium Format CMOS \\
\hline $\begin{array}{l}\text { GoPro Hero Video } \\
\text { Camera }\end{array}$ & $\begin{array}{l}\text { DJI Phantom - } \\
\text { Multirotor }\end{array}$ & $21 \mathrm{~mm}$ & 5.0 & CMOS \\
\hline
\end{tabular}




\section{Table 4 (on next page)}

Disturbance effects on mixed flocks of waterfowl for UAVs launched from different takeoff sites and flown at various approach angles

UAVs were flown either directly perpendicular to a sitting flock of birds or in a tangential flight path running parallel to the main flock of birds. Survey location involved birds at either a large (Llangothlin) or small (Cargelligo) water body. 
Table 4: Disturbance effects on mixed flocks of waterfowl for UAVs launched from different take-off sites and flown at various approach angles. UAVs were flown either directly perpendicular to a sitting flock of birds or in a tangential flight path running parallel to the main flock of birds. Survey location involved birds at either a large (Llangothlin) or small (Cargelligo) water body.

\begin{tabular}{|c|c|c|c|c|c|}
\hline Location & UAV & $\begin{array}{l}\text { No. of } \\
\text { Flights }\end{array}$ & Take-off Location/Direction & Angle of approach & Disturbance Effects \\
\hline $\begin{array}{l}\text { Little Llangothlin } \\
\text { Lagoon }\end{array}$ & Avian-P & 2 & close to shore / away from lake & $\begin{array}{l}\text { Perpendicular to } \\
\text { flock }\end{array}$ & $\begin{array}{l}\text { Birds flew away from shore on } \\
\text { take-off, no disturbance during } \\
\text { flight }\end{array}$ \\
\hline $\begin{array}{l}\text { Little Llangothlin } \\
\text { Lagoon }\end{array}$ & Avian-P & 2 & close to shore / away from lake & Parallel to flock & $\begin{array}{l}\text { Birds swam away from shore } \\
\text { on take-off. Birds flew during } \\
\text { rapid descent to from } 80 \mathrm{~m} \text { to } \\
60 \mathrm{~m}\end{array}$ \\
\hline $\begin{array}{l}\text { Little Llangothlin } \\
\text { Lagoon }\end{array}$ & $\begin{array}{l}\text { Topodrone- } \\
100\end{array}$ & 2 & $\begin{array}{l}700 \mathrm{~m} \text { away from shore, out of } \\
\text { sight/Towards lake }\end{array}$ & Parallel to flock & $\begin{array}{l}\text { No Disturbance at altitudes } \\
\text { above } 60 \mathrm{~m}\end{array}$ \\
\hline $\begin{array}{l}\text { Little Llangothlin } \\
\text { Lagoon }\end{array}$ & $\begin{array}{l}\text { Topodrone- } \\
100\end{array}$ & 2 & $\begin{array}{l}700 \mathrm{~m} \text { away from shore, out of sight/ } \\
\text { Towards lake }\end{array}$ & $\begin{array}{l}\text { Perpendicular to } \\
\text { flock }\end{array}$ & $\begin{array}{l}\text { Birds flew away from shore on } \\
\text { approach at } 80 \mathrm{~m} \text { but became } \\
\text { acclimatised to the UAV. Birds } \\
\text { flew when the UAV banked and } \\
\text { dropped to } 60 \mathrm{~m} \text {. }\end{array}$ \\
\hline $\begin{array}{l}\text { Little Llangothlin } \\
\text { Lagoon }\end{array}$ & Phantom & 2 & close to shore/ vertical take off & $\begin{array}{l}\text { Perpendicular to } \\
\text { flock }\end{array}$ & $\begin{array}{l}\text { Birds were vigilant and swam } \\
\text { slowly away from the UAV }\end{array}$ \\
\hline $\begin{array}{l}\text { Little Llangothlin } \\
\text { Lagoon }\end{array}$ & Skylark II & 2 & close to shore/ directly at flock of birds & Parallel to flock & $\begin{array}{l}\text { Birds flew away on take-off, } \\
\text { and with banking at } 60 \mathrm{~m}\end{array}$ \\
\hline $\begin{array}{l}\text { Little Llangothlin } \\
\text { Lagoon }\end{array}$ & Skylark II & 2 & $\begin{array}{l}\text { 700m away from shore, out of sight/ } \\
\text { Towards lake }\end{array}$ & $\begin{array}{l}\text { Perpendicular to } \\
\text { flock }\end{array}$ & No disturbance \\
\hline $\begin{array}{l}\text { Lake Cargelligo } \\
\text { Sewage Works }\end{array}$ & Skylark II & 2 & $\begin{array}{l}100 m \text { away from shore out of line of } \\
\text { sight/ away from water }\end{array}$ & Parallel to flock & No disturbance at any altitude \\
\hline $\begin{array}{l}\text { Lake Cargelligo } \\
\text { Sewage Works }\end{array}$ & Kraken-130 & 2 & $\begin{array}{l}100 \mathrm{~m} \text { away from shore out of sight/ } \\
\text { vertical take off }\end{array}$ & Parallel to flock & $\begin{array}{l}\text { Birds were vigilant and looked } \\
\text { up at the UAV at altitudes } \\
\text { below } 60 \mathrm{~m} \text { but did not move } \\
\text { from their roost. }\end{array}$ \\
\hline
\end{tabular}

4 
1

Little Llangothlin Lagoon, NSW, Australia

Approximately $50 \%$ of the surface is vegetated and large numbers of birds $(>1000)$ were distributed across the lagoon. Yellow circles represent take-off sites. Red arrows represent approach angles for different flights 

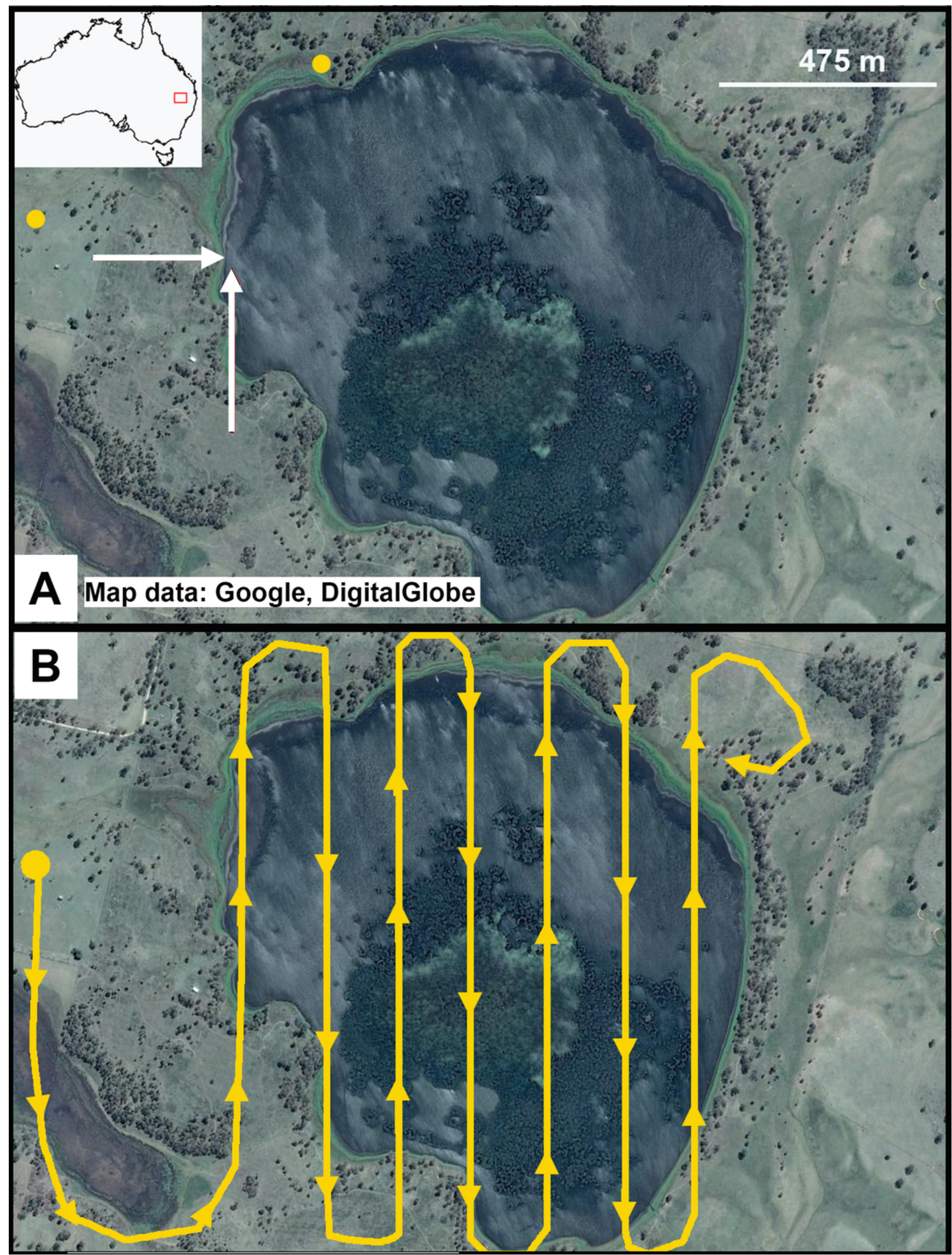
2

Lake Cargelligo, NSW, Australia

The main lake is approximately $24 \mathrm{~km} 2$ and is managed to maintain water levels. The majority of waterfowl in the area congregate on the local sewage works (inset) where all UAV trials were carried out. Yellow circle represents take-off site. Red arrows represent approach angles for different flights 

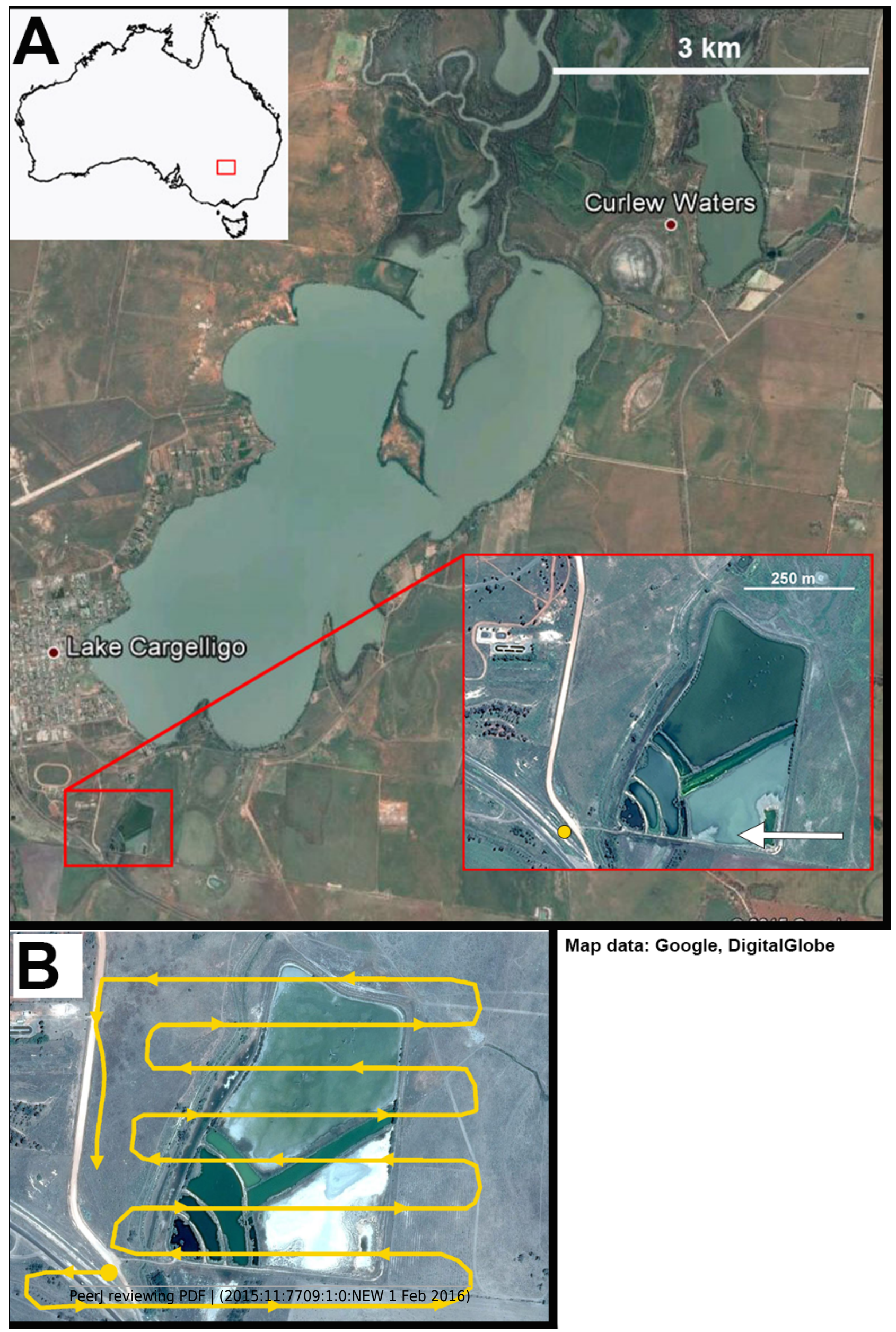

Map data: Google, DigitalGlobe 
3

Examples of UAV models with different wing profiles

A) Avian-P fixed wing UAV, B) Skylark II fixed wing UAV, C) Topodrone-100 fixed wing UAV, resembles bird of prey, D) Kraken-130 multirotor type UAV, E) Phantom multirotor type UAV, F) White-bellied sea eagle, a common avian predator active at each study site 

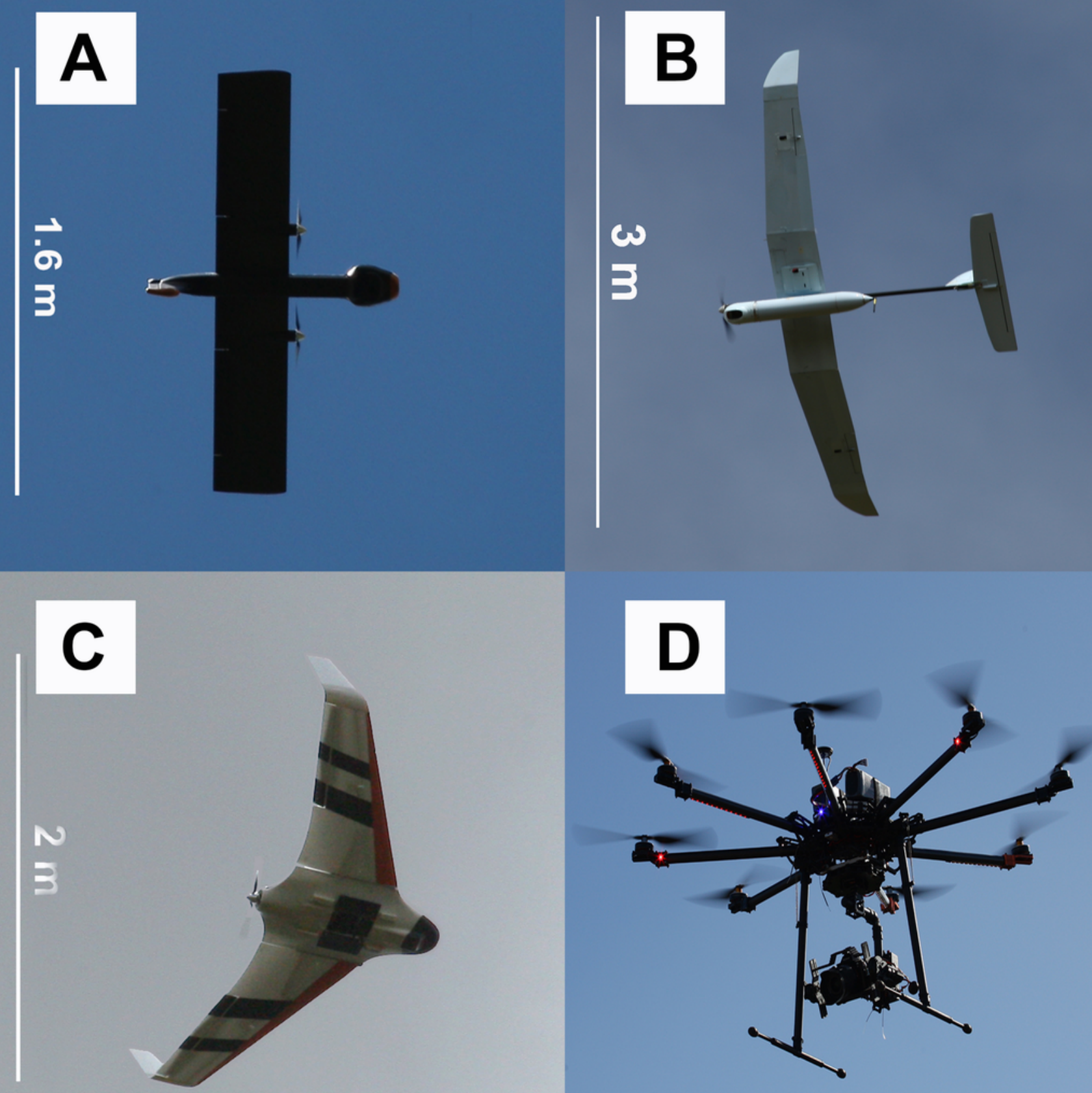

$1.8 \mathrm{~m}$
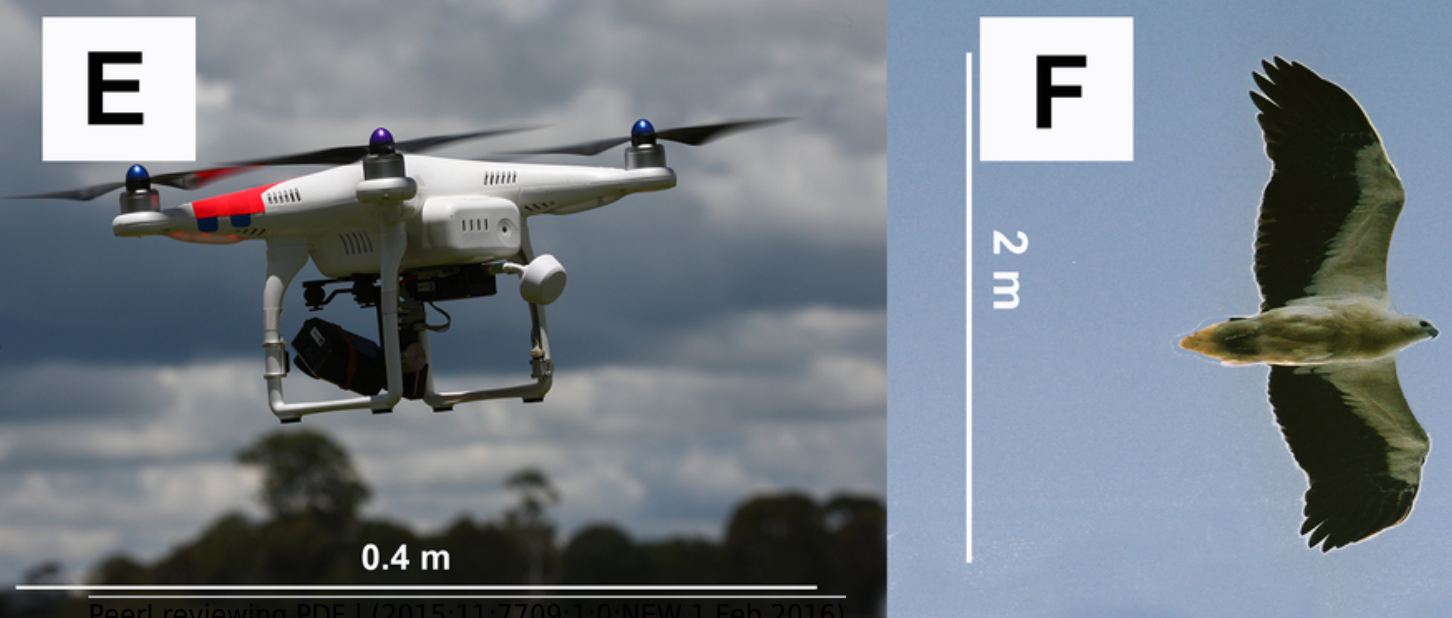
4

Examples of images taken using the Phase-1 medium format digital camera

Species that are similar in size and shape can be clearly differentiated in photos taken from $60 \mathrm{~m}$ above the flock with an $80 \mathrm{~mm}$ lens. Smaller birds such as swallows and black winged stilts can also be easily identified. In the bottom right panel a Pacific black duck can be seen tilting its head to look directly up at the camera

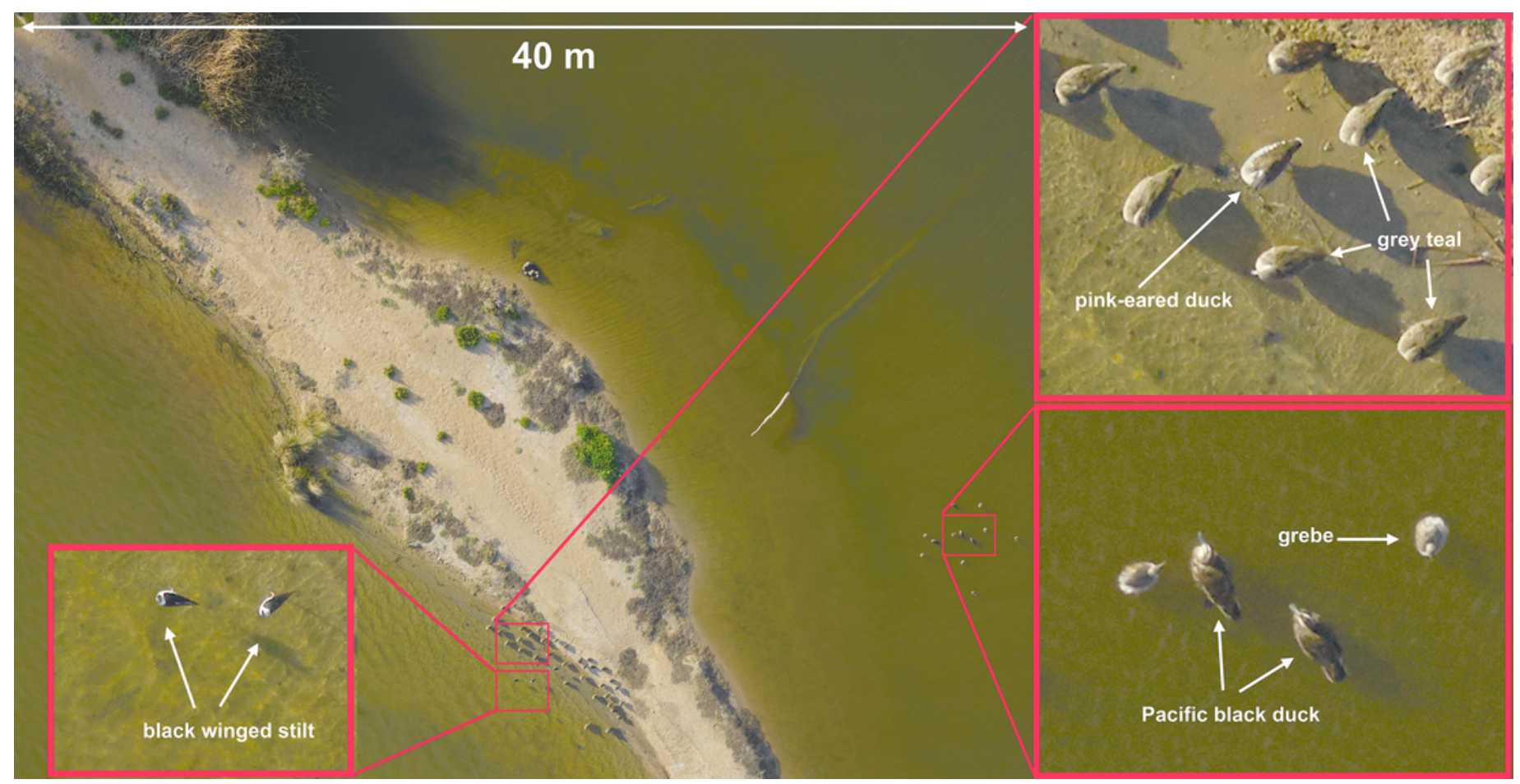


5

Examples of images taken using the Sony A7-R digital camera

Species that are similar in size and shape can be clearly differentiated in photos taken from $50 \mathrm{~m}$ above the flock with a $70 \mathrm{~mm}$ lens. Smaller birds such as swallows and black winged stilts can also be easily identified

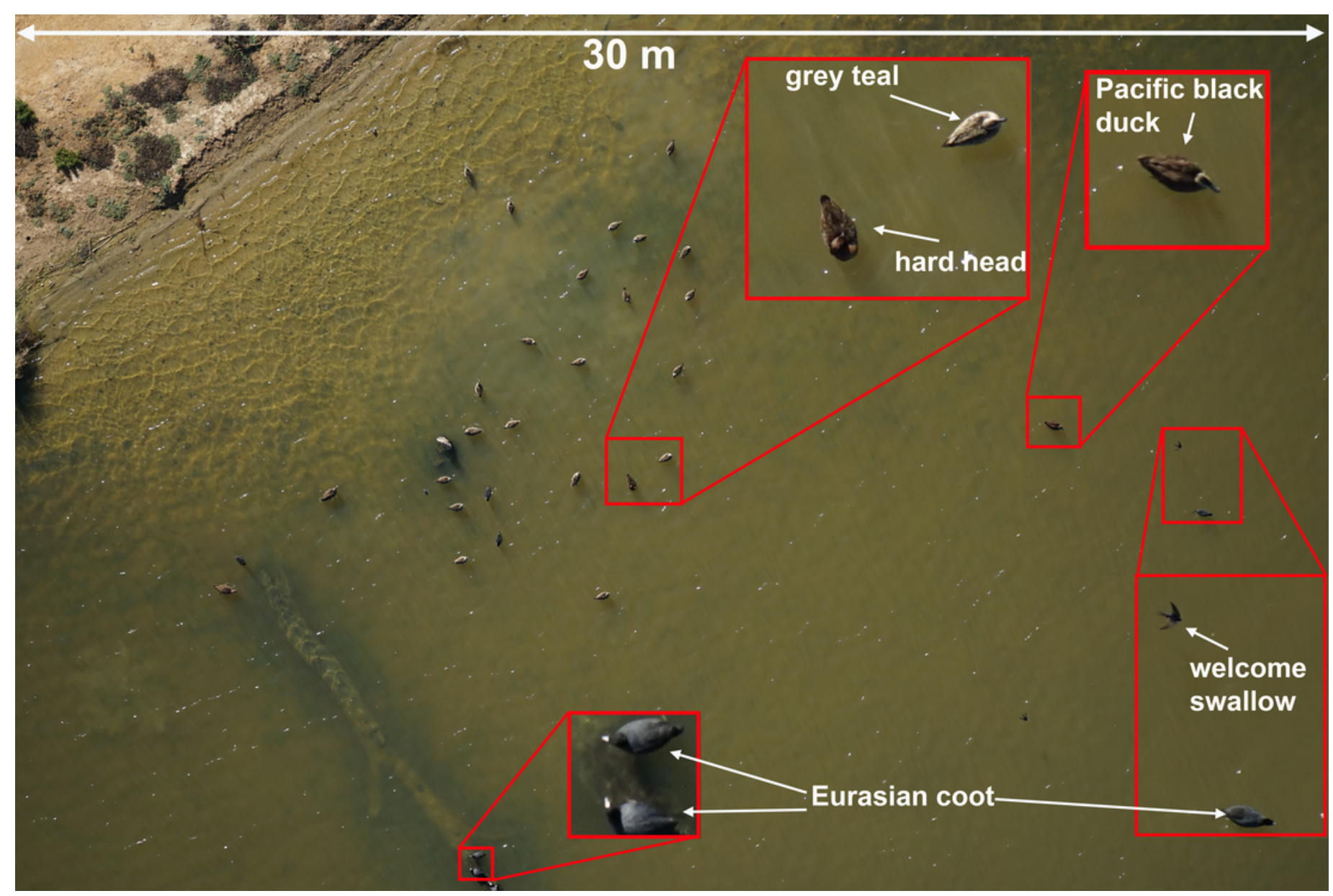

